\title{
La guerra y los no nacionales: la Segunda Guerra Mundial y las radicalizaciones de la Campaña de Nacionalización en Porto Novo, Brasil (1939-1945)
}

\author{
War and the non-nationals: World War II and the \\ Nationalization Campaign's radicalization in Porto Novo, Brazil \\ (1939-1945)
}

João Vitor Sausen*

\section{RESUMEN}

A partir de 1937 Brasil pasó a ser gobernado por una dictadura llamada Estado Novo (1937-1945). Durante el periodo que estuvo en el poder, este régimen tuvo como una de sus principales banderas la nacionalización de grupos inmigrantes, así como de sus descendientes que vivían en el país. Además, durante la Segunda Guerra Mundial y la declaración de guerra de Brasil a Alemania en 1942, fueron aplicadas medidas de nacionalización más rigurosas a los germano-hablantes en el país. En Porto Novo, una región habitada, en aquella época, en gran parte por hablantes de alemán, la participación de Brasil en la Segunda Guerra Mundial generó dos momentos de expulsión de residentes alemanes y rumanos, el primero fue en agosto de 1942 y el segundo en febrero de 1943. A partir de ambos eventos, la presente investigación tiene como propósito presentar ambas expulsiones de extranjeros y analizarlas desde la perspectiva de la nacionalización. Para ello, utilizaremos obras memorialísticas y entrevistas referentes a dicho periodo y a los eventos específicos.
Palabras clave:

Porto Novo, nacionalización, Estado Novo brasileño, migraciones forzadas.

\footnotetext{
* Brasileño. Profesor y Licenciado en Historia, Universidad Federal de Santa María, Brasil. Estudiante de Magíster del Programa de Posgrado en Historia de la Universidad Federal de Santa María, PPGH/UFSM, Brasil. Becario CAPES/DS. ORCID: https://orcid. org/0000-0002-3819-6032. E-mail: sausenjoaovitor@gmail.com

* Nota editorial: Este artículo es la traducción en español del artículo original en portugués titulado "A guerra e os não nacionais: a Segunda Guerra Mundial e as radicalizações da Campanha de Nacionalização em Porto Novo, Brasil (1939-1945)". La traducción fue realizada por Macia de Mello con la conformidad del autor del trabajo.
} 


\section{SUMMARY}

In 1937 Brazil was ruled by a dictatorship called Estado Novo (1937-1945). During its period in power, this regime had as one of its main banners the nationalization of immigrant groups and their descendants living in the country. In addition, during World War II and Brazil's declaration of war against Germany in 1942, the country applied more rigorous nationalization measures to German speakers. Brazil's participation in World War II generated two moments of expulsions of German and Romanian residents. First in August 1942 and the second in February 1943, mainly in Porto Novo, a region inhabited, at that time, mainly by German speakers. Based on both events, the purpose of this research is to present both expulsions of foreigners and analyze them from the perspective of naturalization. For this purpose, we will use memorial works and interviews related to the period and the specific events.
Keywords: Porto Novo, nationalization, Brazilian Estado Novo, forced migrations. 
Porto Novo es una región histórica del Este del Estado brasileño de Santa Catarina, ubicado cerca de la frontera del estado de Rio Grande do Sul y entre el límite político de Brasil con la República Argentina. Actualmente se encuentra entre los municipios de Itapiranga, São João do Oeste y Tunápolis, también forma parte de Iporã del Oeste. Su formación histórica se dio a partir de una colonización liderada por la Volksverein für die deutschen katholiken in der Rio Grande do Sul ${ }^{1}$, dirigida a hablantes de alemán y católicos (Werle, 2011). Bajo este recorte étnico y religioso, ha recibido mayoritariamente a inmigrantes de origen alemán nacidos en el estado vecino de Rio Grande do Sul, descendientes de inmigrantes alemanes que llegaron a Brasil en el siglo XIX (Jungblut, 2011). En el siguiente mapa está representada la localización conjunta de los actuales municipios que conforman la región histórica de Porto Novo:

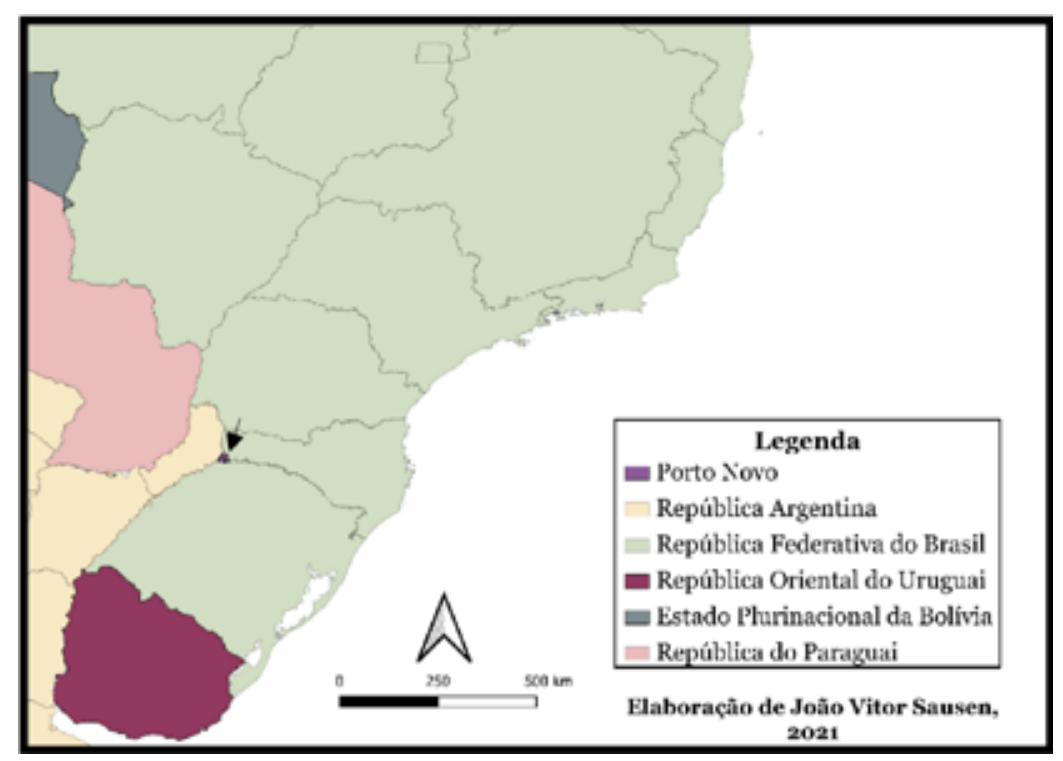

Figura 1. Mapa de Porto Novo, Santa Catarina, Brasil

Fuente: Elaboración propia a partir del software gratuito QuantumGis3 y de las bases cartográficas digitales de IBGE. Mallas digitales. Disponible en https://mapas.ibge.gov. $\mathrm{br} /$ bases-e-referenciais/bases-cartograficas/malhas-digitais. Revisado el 16-VI-2021.

$1 \quad$ En español, Sociedad Popular para alemanes católicos de Rio Grande do Sul. 
Durante la década de 1930 Porto Novo recibió un gran número de alemanes y rumanos de origen alemán, que huyeron del contexto de inestabilidad económica y política de Europa (Mayer, 2017). Muchos de estos alemanes formaron la comunidad de Linha Presidente Becker, ubicada cerca del Río Peperi-Guaçu, que marca la división fronteriza brasileña con la República Argentina (Rohde, 2011).

Sin embargo, con el Estado Novo Brasileño (1937-1945) y la Segunda Guerra Mundial (1939-1945), la formación popular de Porto Novo pasó a ser un problema para la política de nacionalización conducida por el gobierno. Bajo ese contexto se generó, entre otras decisiones más radicales, la expulsión de los alemanes y rumanos de la ciudad, tema que será tratado en el presente artículo. En la imagen a continuación podemos visualizar la parte urbana de Porto Novo en 1940:

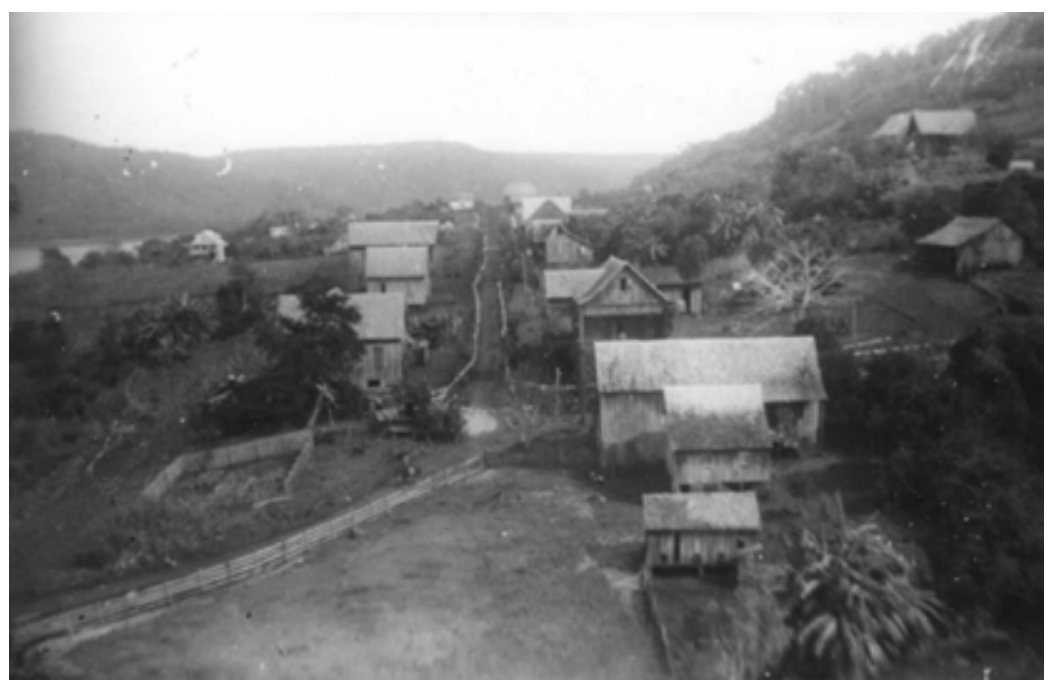

Figura 2. Vista del sector urbano de Porto Novo, 1940.

Fuente: Stahl y Mayer (2019: 27).

Este trabajo se centra en el campo de investigación sobre la nacionalización en Brasil, conformado por un gran número de obras, desarrolladas durante varias décadas. De este modo, es necesario relacionar algunos trabajos relevantes para la presente investigación y que constituyen una base bibliográfica para dichos estudios. 
Uno de estos ejemplos es el trabajo del investigador René Gertz (1998). El autor observa que las políticas públicas aplicadas a la nacionalización de los grupos de origen teutón tuvieron mayor importancia a partir del Estado Novo brasileño (1937-1945) y la participación del país en la Segunda Guerra Mundial (después de 1942, contra los países del Eje). Según Gertz, existía la idea de que los inmigrantes alemanes y sus descendientes se aislaban del resto de la población del país y se negaban a integrarse, lo que significaba un supuesto "peligro alemán" (una amenaza imperialista que los utilizaría como agentes a favor de los intereses del Imperio alemán en el país). De este modo, preocupados por la defensa nacional, se dio inicio al proceso de nacionalización de los alemanes y sus descendientes establecidos en Brasil.

Arthur Blásio Rambo (1994) señala que la principal evidencia de que los núcleos de descendientes de inmigrantes seguían sin integrarse al país, era el hecho de que preferían usar la lengua alemana en lugar del portugués. Sin embargo, no es que la lengua alemana estuviera asociada a la idea de una no-integración, sino a la mantención de los aspectos culturales provenientes de la región de origen de sus antepasados y, por lo tanto, pilares de la sociabilidad de los núcleos de descendientes de inmigrantes.

Además, Giralda Seyferth (1994) defiende que el proceso de migración representaba un acto de ruptura con la patria de origen. En este sentido, es común notar en las narrativas de descendientes de inmigrantes un acto inaugural en la persona del viajero que cruzó el Atlántico y se estableció en Brasil, de manera que las historias familiares suelen iniciarse en aquel sujeto. Asimismo, las manifestaciones culturales de los descendientes de inmigrantes no tenían relación con un aislamiento con el resto del país, y era común la búsqueda por la integración política con la patria brasileña.

Sin embargo, de acuerdo con Rosane Neumann (2003), la lengua portuguesa era considerada como uno de los principales pilares de la nacionalidad brasileña en aquel periodo. Por ello, los descendientes nacidos en Brasil que no hablaban portugués eran clasificados como ciudadanos de segunda categoría. Además, las iniciativas de nacionalización tenían como propósito limitar o prohibir manifestaciones en otras lenguas, así como tener un control sobre las instituciones esco- 
lares como forma de desmantelar la autoorganización de los núcleos descendientes de inmigrantes.

El brasilianista Jeffey Lesser (2015), al analizar la inmigración a Brasil y la integración de los inmigrantes y sus descendientes, observa que las visiones acerca de la inmigración sufrieron profundas alteraciones a partir de la década de 1930. Según el autor, una de las razones fue el desempleo creciente, que transformó la presencia y la entrada masiva de los inmigrantes en un gran problema. De este modo, fue impuesto un sistema de cupos para el ingreso de extranjeros, e incluso la prohibición en el caso de los judíos. Además, la mano de obra brasileña pasó a ser prioridad frente a los trabajadores extranjeros. Con el Estado Novo, las imposiciones sobre los inmigrantes y sus descendientes presentes en el país fueron aún mayores, lo que significó limitaciones tanto a las actividades culturales como a las manifestaciones en otras lenguas que no fuesen la portuguesa, así como también la remoción de los inmigrantes o sus descendientes de puestos directivos de las instituciones escolares.

Leandro Mayer (2017) analiza la nacionalización en Porto Novo (Santa Catarina) a partir de la persecución al núcleo de la Ação Integralista Brasileira (AIB) ${ }^{2}$ a nivel regional. Para ello, se basaba en el análisis del proceso de Crimen de Seguridad Nacional instaurado contra Anton Kliemann, comerciante local y líder integralista en Porto Novo. De acuerdo con Mayer (2017), Kliemann y otros integralistas de la región fueron perseguidos, encarcelados y torturados bajo el argumento de que se trataba de partidarios nazistas y, por lo tanto, agentes enemigos del país.

En relación con las iniciativas de nacionalización desarrolladas en Porto Novo durante el Estado Novo brasileño, hemos notado que las iniciativas afectaron a diversos ámbitos y variaron a lo largo del periodo (Sausen, 2019). En este sentido, en un primer momento, fueron estatizadas las instituciones escolares locales, los integrantes de la Ação Integralista Brasileira fueron perseguidos y, posteriormente, hubo un fomento constante a las actividades patrióticas, fueron prohibidas las

2 Partido de extrema derecha y de orientación fascista puesto en ilegalidad a partir del golpe de 1937 y la instalación del "Estado Novo" en el país. Para más informaciones sobre la AIB ver: Gonçalves y Neto, 2020. 
manifestaciones en alemán, así como también fueron expulsados los alemanes o rumanos que vivían en Porto Novo. Este último tema será tratado en el presente trabajo.

Para la realización de dicho análisis, a su vez, haremos uso de un conjunto de fuentes bibliográficas y documentales que narran los eventos ocurridos en aquel periodo. Está incluido en este conjunto el Livro Tombo da Paróquia de Itapiranga, que funcionaba como un registro constante de todo lo que ocurría en la región, desde la perspectiva de los religiosos que administraban la parroquia local. Además de esta fuente, también será utilizada una compilación de estos registros realizada en 2016, debido a la celebración de los 90 años de la existencia de la parroquia (Spohr, 2016).

En relación con las demás fuentes, nos basamos en la obra memorialística de Luiz Heinen (1997), religioso de actuación local, que recopila informaciones sobre los eventos de la Segunda Guerra Mundial, así como también en entrevistas con los sujetos que fueron el blanco de las iniciativas estatales de nacionalización. Además de esta obra, nos basamos en las memorias de Maria Wiersch Rohde, publicadas originalmente en alemán en 1951 y traducidas al portugués en 2011. Otro trabajo que utilizaremos es el de Ida Müller Welter, publicado en una edición bilingüe en 2010. Ambas recopilan memorias personales del periodo y ofrecen perspectivas importantes en relación con la nacionalización en el ámbito local. Junto con estas obras, también serán utilizadas entrevistas realizadas por Roque Jungblut con personas que participaron o presenciaron los eventos del periodo y que fueron publicadas en 2011.

\section{El Estado Novo brasileño y la nacionalización de Porto Novo}

Hasta 1930 Brasil fue gobernado por un conjunto de diversas oligarquías, especialmente las del Sudeste del país. La década de 1920 constituyó, sin embargo, un momento de explosión contestataria de diversos grupos ante el contexto político brasileño, que dio origen, en 1930, a la toma del poder por la Aliança Liberal, después de la derrota de ésta en las elecciones del año anterior (Ferrera y Pinto, 2018). A raíz de este proceso, llegó al poder Getúlio Vargas, exministro del gobierno de Washington Luiz (depuesto en 1930) y expresidente del Estado del 
Rio Grande do Sul. Con el nuevo grupo en el poder fueron reorganizados los ordenamientos nacionales, así como ocurrieron nuevos movimientos contestatarios, como los paulistas, en una revuelta fracasada en 1932, y los comunistas, en 1935, movimiento que también fracasó (Levine, 2001). Después de redactar una nueva Constitución para el país, en 1934 Vargas fue electo presidente por el Parlamento.

En 1938 fueron agendadas elecciones presidenciales que anunciaban el fin de su periodo en el poder. Sin embargo, en 1937, como forma de perpetuación en el gobierno, fue tramada la noticia falsa de un supuesto complot judío-comunista que planeaba tomar el poder en el país, como justificación para un autogolpe que mantuvo a Vargas en el poder, con el apoyo de militares y varios sectores de la sociedad brasileña (Levine, 2001). En aquel mismo año también fue redactada una nueva Constitución, de carácter centralista.

Este nuevo periodo, conocido como Estado Novo, se extendió hasta 1945, cuando Getúlio Vargas fue depuesto del poder por las Fuerzas Armadas. En ese contexto, el país centró sus esfuerzos en la nacionalización de los grupos inmigrantes y de sus descendientes que, en el caso de los hablantes de alemán, eran considerados como "quistes étnicos", grupos que se mantenían apartados y no integrados al resto de la sociedad brasileña (Mayer, 2016). En este sentido fue conducida la llamada “Campaña de Nacionalización", a favor de la asimilación de los descendientes de los inmigrantes que vivían en el país.

Bajo este aspecto, en una investigación anterior (Sausen, 2019) nos enfocamos en analizar cuáles fueron las principales medidas que el Estado Novo buscó implementar para nacionalizar a la comunidad de inmigrantes de Porto Novo. Identificamos que, en un primer momento, hubo una disputa por las estructuras de enseñanza local. Estas, a su vez, se basaban en una autoorganización por parte de los residentes y eran financiadas por los mismos, ya que las instituciones públicas estaban ausentes o eran insuficientes. El control pedagógico y la propiedad de las construcciones pertenecían a la Iglesia católica, cuya parroquia en Porto Novo estaba bajo la esfera de la Orden Jesuita. Usualmente la estructura de la Iglesia era la misma que la de las escuelas y, en el caso del profesor, este era pagado por la propia comunidad, recibiendo una casa y una porción de tierra para asegurar su subsistencia y la de su familia (Eidt, 2016). 
En este sentido, a partir de 1935 el Estado de Santa Catarina, representado por su gobernador, Nereu Ramos, ya buscaba un mayor control sobre las estructuras de la enseñanza privada (Moraes, 2017). En 1938, el Estado brasileño pasó a ejercer una presión sobre este aspecto y condujo a la estatización de las estructuras de enseñanza, así como su malla curricular, además de elegir profesores que fuesen capaces de enseñar en Porto Novo (Livro Tombo da Paróquia de Itapiranga, 1938).

Además de la búsqueda del monopolio de la enseñanza, el Estado Novo también trató de desmovilizar y perseguir al núcleo de la Ação Integralista Brasileira (AIB) en Porto Novo. Este grupo político, de extrema derecha, se formó en 1932 y tuvo un crecimiento exponencial durante la década, especialmente en las regiones de la colonización alemana e italiana. Asimismo, el grupo político apoyó el golpe de Estado de 1937, pero fue desmovilizado por el Estado Novo con el apoyo de los demás partidos políticos. La insatisfacción de sus integrantes llevó a un intento fracasado de golpe de Estado en 1938 (Gonçalves y Neto, 2020).

A raíz de este proceso, los integralistas fueron perseguidos y eran usualmente vinculados a los nazistas, tema que les aseguraba una asociación a actividades antinacionales durante la Segunda Guerra Mundial (Mayer, 2016). Durante la década de 1940 la persecución a los exintegrantes del núcleo integralista local permaneció, y hubo encarcelamientos y tortura, todo bajo la excusa de un supuesto contrabando de armas desde Argentina realizado por comerciantes vinculados al partido, hecho que nunca fue comprobado (Mayer, 2016).

En la década de 1940 surgieron otras tres iniciativas de nacionalización profundamente vinculada a la Segunda Guerra Mundial. La primera de ellas fueron los intentos de inculcar el patriotismo en la comunidad local a través del himno nacional, ceremonias de izamiento de la bandera nacional, desfiles militares, entre otros. Todos tenían como propósito fomentar una identidad nacional en los habitantes locales (Sausen, 2019). Dicho aspecto se confrontaba directamente con dos medidas violentas impuestas en tal contexto.

Estas ocurrieron a partir de 1942, cuando Brasil le declaró la guerra a la Alemania nazi y se posicionó en la Segunda Guerra Mundial. Tal hecho trajo profundas consecuencias para los alemanes y sus descen- 
dientes que se habían establecido en el país. Con el conflicto, fueron prohibidas todas las manifestaciones públicas y privadas en alemán en Porto Novo (Sausen, 2019). El delito era castigado duramente con un periodo de encarcelamiento en una cárcel local. Otro aspecto surgido a raíz del conflicto fue la expulsión de alemanes y rumanos de la región, lo que ocurrió a partir del mes de agosto de 1942 y que será tratado a continuación.

\section{Agosto de 1942: “A Coluna dos 13"}

En su esfuerzo memorial, Maria Rohde publicó trechos del diario de vida de su hija, Daniela, refiriéndose a ese periodo. En relación con el día 23 de agosto de 1942 señala: "hoy supimos que en Itapiranga todos los hombres alemanes fueron arrestados y que 11 se habían escapado a Argentina como precaución" (Rohde, 2011: 245). Los presos citados por Daniela Rohde corresponden a los perseguidos políticos anteriormente citados. Los que se escaparon a Argentina, serán tema de este tópico.

En el mes de agosto de 1942, Brasil, después de una serie de conflictos que involucraron el hundimiento de varias embarcaciones mercantes y de transporte del país en la costa marítima, le declaró la guerra a la Alemania nazi (Sausen, 2019). En Porto Novo, el contexto de guerra hizo que los alemanes que vivían en la región de Linha Presidente Becher, limítrofe con la República Argentina, se refugiaran en el país vecino. Luiz Heinen (1997) defiende que la búsqueda por refugio en Argentina ya había sido determinada por el grupo debido a los posibles arrestos a raíz de la nacionalidad de los sujetos y la condición de guerra. Heinen también menciona el caso de Wilhelm Rost, uno de los participantes de la fuga:

"Al ocurrir los primeros arrestos, a finales de agosto de 1942, Wilhelm Rost se despidió de su familia, subió al caballo cerca de la plaza, como hacía de costumbre para ir a trabajar en su propiedad rural.

A las 9 de la mañana buscó a mi padre en la plantación, su $2^{\circ}$ vecino. Ni apeó. 'Amigo y vecino, mi familia y yo necesitamos de su ayuda. Se iniciaron los arrestos en Itapiranga. Algunos compañeros y yo no deseamos el sufrimiento de la cárcel, por motivo de la guerra. Por ello, nos vamos a Argentina. Suplico a usted que cuide de mi propiedad y de los animales como si fuera suyo: plante, cose- 
che, venda, carnee, compre lo que sea necesario. De vez en cuando entregue algún dinero, caso sobre algo, a mi mujer. No es necesario que sea mucho, pues ella recibe algo de dinero como matrona. Muchas gracias por este favor. Hasta pronto' Y se fue. Mi papá ni siquiera pudo decir una palabra, asustado con tanta novedad. Quiso ponerse de acuerdo, hacer un contrato particular. Rost solamente saludó gritando: 'No te preocupes, todo saldrá bien. Nos vemos a la vuelta, después de la guerra”' (1997: 184).

Este relato entrega dos informaciones relevantes. La primera es que solamente los hombres alemanes dejarían la región en búsqueda de refugio, mientras que sus familiares permanecerían en Brasil. El objetivo era esperar en el país vecino hasta que se terminase el conflicto. Más allá de estos aspectos, Wilhelm Rost no fue el único en sumarse a este grupo. Heinen (1997) estima que el número de refugiados hacia la República Argentina era de 20 a 25 hombres, mientras que Wolfgang Lengert, en una entrevista para Roque Jungblut (2011), afirma que se trató de trece sujetos, hecho por el cual él denomina el evento como “Coluna dos 13". De acuerdo con Lengert, la trayectoria del grupo fue la siguiente: "fueron hasta la ciudad de Oberá [hasta entonces Territorio Nacional de Misiones, Argentina] y desde allí algunos se fueron a otros lugares. Algunos se quedaron allí por varios años y otros nunca más volvieron. La fuga duró seis días, siguiendo algunos caminos y senderos existentes en la selva de Argentina" (Jungblut, 2011: 473). Herman Scholz, otro entrevistado por Roque Jungblut, y participante del episodio, revela que:

"No todos los que entraron en la selva de Argentina para huir tuvieron la valentía para seguir. Primero, entramos en el bosque cerca de dos kilómetros y observamos durante dos días parar asegurarnos que nadie nos perseguía. Bruno Eidt, Heine Neumann, Guinter Prost, Ludwig Lengert, Bernard Engesser desistieron de la fuga y volvieron. Fueron arrestados. A Heine lo derrumbaron del caballo. Le dispararon al animal. Entramos a São Ludgero [Localidad de Porto Novo] y seguimos un camino marcado por los troncos de árbol. Nos llevamos dos caballos. Yo tenía 20 años. Trabajé durante tres años en una maderera y dos años más de empleado en un comercio de Oberá. El sueldo era bueno. Regresé a pedido del país (...)" (Junblut, 2011:474). 
El camino recorrido por el grupo también fue narrado por Luiz Heinen (1997), que determinó que el grupo cruzó el Río Peperi-Guaçu (límite político entre la República Argentina y Brasil) hacia la ciudad de San Pedro, en Misiones. Tales hechos, las ciudades de destino y el establecerse en otro país parecen indicar que el grupo conocía bien aquella región, y no se dirigían a localidades totalmente desconocidas. En el mapa a continuación se encuentra demarcada la región de Oberá en relación a Porto Novo:

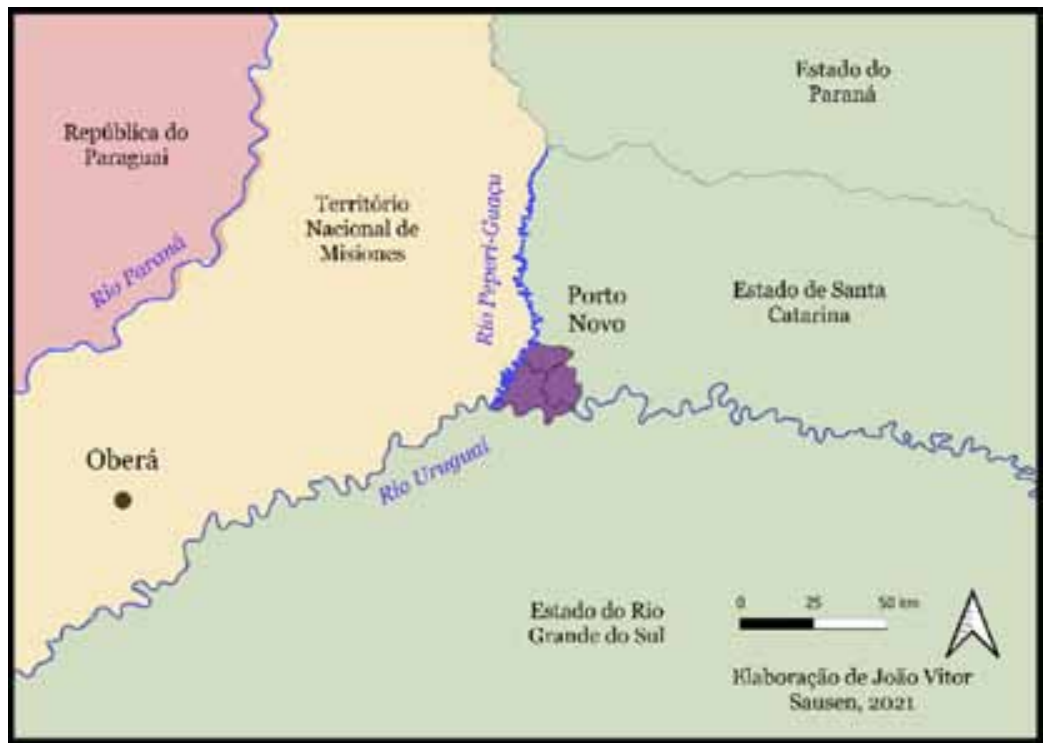

Figura 3. Región de Oberá, Santa Catarina, Brasil.

Fuente: Elaboración propia a partir del software gratuito QuantumGis3 y de las bases cartográficas digitales de IBGE. Mallas digitales. Disponible en https://mapas.ibge.gov. br/bases-e-referenciais/bases-cartograficas/malhas-digitais, y de las herramientas del software Google Earth. Revisado el 16-VI-2021.

Con relación al Territorio Nacional de Misiones ${ }^{3}$, Anne Saint Sauveur-Henn Sauntlh habla sobre la existencia de diversas colonizaciones formadas por inmigrantes alemanes, como Eldorado, emprendimiento del alemán Adolfo Schwelm y Montecarlo. Respecto de la localidad de Oberá (anteriormente conocida como "Yerbal Viejo"), Arthur Blásio Rambo afirma que se trataba de una colonización organizada por el

3 En la actualidad, y desde 1953, es una provincia de la República Argentina. 
gobierno argentino y que, para este tipo de iniciativa, “(...) se dirigían preferentemente a los inmigrantes alemanes en los años posteriores al término de la Primera Guerra Mundial" (1994: 124). Además, el autor también destaca una masiva presencia de alemanes en Misiones en aquel periodo, incluso calculando su número en 25 mil personas hacia 1925. En este sentido, el grupo de alemanes que abandonó Porto Novo debido a posibles persecuciones y arrestos a raíz de la guerra, se fueron a una región donde había una significativa comunidad de inmigrantes de un origen semejante al suyo.

Antes de su regreso, el grupo se comunicaba con sus familiares y la región de Porto Novo a través de los balseros o de los comerciantes que circulaban en la región (Heinen, 1997). El destino de los refugiados, a su vez, fue variado. Como es el caso de los ya citados Wilhelm Rost y Herman Scholz, quienes permanecieron en la República Argentina hasta después del conflicto, cuando regresaron a Porto Novo. Y, tal como fue citado, algunos desistieron de la fuga aun en los primeros días, y otros decidieron no vivir más en Brasil (Jungblut, 2011).

\section{Febrero de 1943: "La Caravana de la Muerte"}

En febrero de 1943, como afirma en sus memorias Maria Wiersch Rohde (2011), todos los extranjeros residentes en Porto Novo fueron obligados a emigrar a otra región, ubicada a más de 150 kilómetros de distancia, hacia al interior del país, conocida como Xanxerê. Este evento fue denominado por la autora como "Caravana de la Muerte". En esta región había funcionado una colonia militar y era mantenido un contingente policial (Crestani, 2019), hecho que posiblemente estaría vinculado a la elección de esa región como lugar de destino designado a los ciudadanos de países enemigos en aquel periodo. En el mapa a continuación se puede observar la localización de Xanxerê en relación a Porto Novo: 


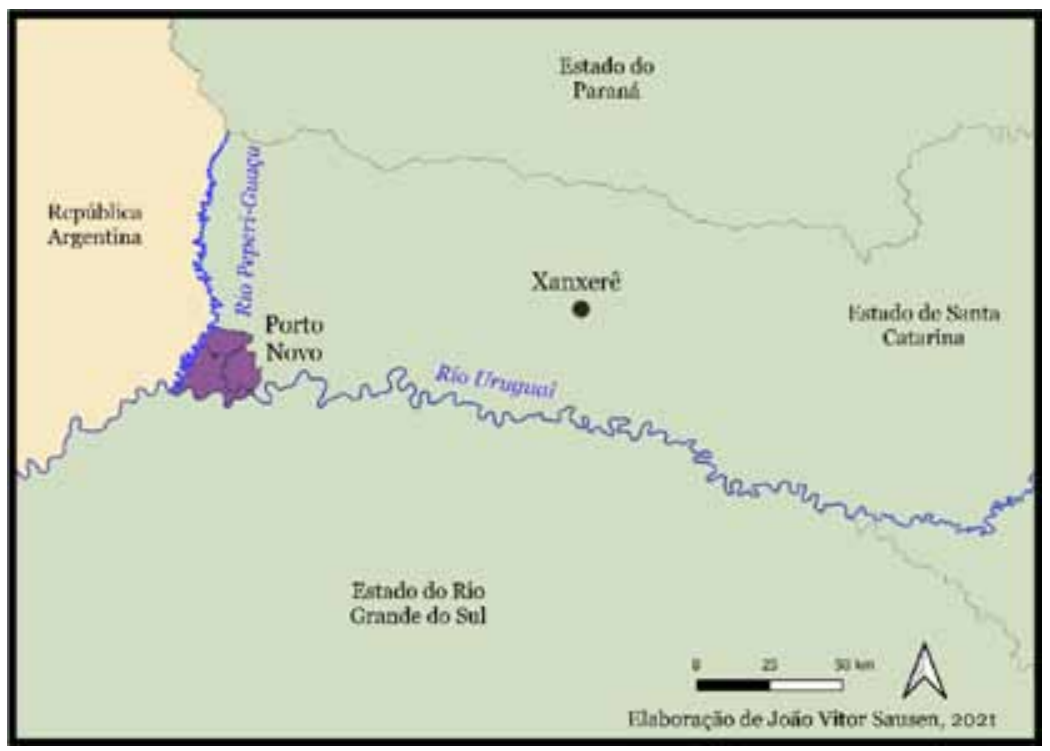

Figura 4. Localización de Xanxerê, Santa Catarina, Brasil.

Fuente: Elaboración propia a partir del software gratuito QuantumGis3 y de las bases cartográficas digitales de IBGE. Mallas digitales. Disponible en https://mapas.ibge.gov. $\mathrm{br} /$ bases-e-referenciais/bases-cartograficas/malhas-digitais, y de las herramientas del software Google Earth. Revisado el 16-VI-2021.

Los registros religiosos de Itapiranga, a principios de aquel año, ya indicaban que los extranjeros serían removidos de Porto Novo. De hecho, se hizo una fiesta con el objetivo de celebrar la "retirada de los extranjeros de 'Itapiranga a Xanxerê", el 5 de enero de 1943 (Spohr, 2016). La decisión, de acuerdo con Roque Jungblut (2011), habría sido publicada en diciembre de 1942. Pero la notificación oficial llegó solamente el 3 de febrero de aquel año, de acuerdo con lo relatado por Maria Wierch Rohde (2011):

“2 de febrero (...) todos los extranjeros recibieron la orden de presentarse, el 3 de febrero, en la comisaria de Itapiranga.

3 de febrero, temprano por la mañana, todos se movieron. Un día muy caluroso, la tierra en la carretera tapaba los pies, debido a la sequía que aún duraba meses. La atmósfera parecía estar tomada de humo, provocada por los incendios en el bosque que estaba alrededor. Cuando amaneció fuimos a caballo con el Sr. Baptista Hofer hasta el núcleo urbano de Itapiranga. Allí me encontré con 
todos los extranjeros, aún esperando, después de la cabalgada torturante y el calor de matar, procurando refugiarse en cualquier pequeña sombra que fuese posible encontrar. Jóvenes y viejos, la mayoría hombres. Mujeres, solamente aquellas que, igual que yo, estaban solas, cuyos esposos habían huido, cruzando la frontera a Argentina. Todo el centro de la ciudad estaba repleto de caballos. Permanecimos parados en fila delante de la comisaría. Cada uno esperando para ser despachado. El trámite era rápido. A nosotros nos entregaban nuestros documentos y recibíamos la orientación de estar listos para viajar, en 10 días, cuando deberíamos retirar los documentos necesarios para el viaje y partir al exilio - en XaximXanxerê. Ante cualquier argumento que intentaba probar la imposibilidad de tal medida, la respuesta era siempre la misma: aquel que no dejara su casa, voluntariamente, hasta el 13 de febrero, sería retirado de allí por la fuerza, por los soldados, y obligado a marcharse" (2011: 262).

En este sentido, Rohde informa el corto plazo que les quedaba a los extranjeros para prepararse y establecerse en una región distinta a la cual vivieron desde hacía muchos años. Sin embargo, a partir de una observación de las nacionalidades expulsadas de Porto Novo así como en tres trayectorias, es posible percibir que la orden de salida no se refería a todos los extranjeros establecidos en la región, sino solamente a dos nacionalidades en específico. En el caso de la propia Maria Wiersch Rohde, nacida en Alemania, casada con un alemán, pero ciudadana estadounidense ${ }^{4}$, fue excusada de la migración, ya que estaba vinculada a un país aliado en la guerra.

Otro caso significativo fue el de Anton Ruscheinki, nacido en Bessarábia, entonces parte de Rumania, cuyos padres eran rusos y que tenía algunos hermanos brasileños. Ruscheinski fue el único de su familia forzado a migrar, aunque las únicas nacionalidades forzadas a salir eran la alemana y la rumana (Jungblut, 2011). Sin embargo, tal hecho estaría relacionado a la situación de la guerra, pues Alemania y Rumania estaban del lado opuesto a Brasil. Además de Ruscheinski, es preciso citar el caso de Ida Müller Welter, narrado en su autobiografía:

4 La familia de Maria Wiersch Rohde emigró de Alemania a Estados Unidos y, después de la Primera Guerra Mundial, dejó este país rumbo a Brasil (Eidt, 2020). 
"Nosotros, los rumanos, debíamos ser transportados para lejos de la frontera. Era necesario vender todo lo que no cabía en la carroza, o más bien, regalar. Las casas fueron alquiladas, los bueyes tirando las carrozas, y se iban las familias. Mi madre y mis hermanos también siguieron el mismo destino. Yo ya estaba casada con Adolfo Welter, un teutón brasileño, así que podría quedarme hasta un nuevo aviso, dijeron. Esa orden nunca llegó" (Welter, 2010: 33).

De esta manera, la expulsión de los extranjeros afectó solamente a dos nacionalidades y resguardaba aquellas personas que habían constituido vínculo matrimonial con brasileños, tal como Roque Jungblut (2011) también plantea, lo que permite percibir una noción de nacionalización a través de estas relaciones. La base para la expulsión de los extranjeros del perímetro inmediato de la frontera, a su vez, se encontraba en el Decreto Ley No 1.164, publicado el 18 de marzo de 1939 (Brasil, 1939), de acuerdo con lo que también había sido planteado por Roque Jungblut (2011). Esta legislación definía una serie de limitaciones para la presencia de extranjeros en la frontera, como por ejemplo las concesiones de tierra a 15 kilómetros del límite político y la prohibición de la venta de tierras a los extranjeros en un rango de 30 kilómetros. En el contexto de la guerra, esta legislación parece haber sido la base para la expulsión de los alemanes y rumanos de los mismos perímetros sobre los cuales esta deliberaba.

Sin embargo, la orden de expulsión no fue permanente. Maria Wierch Rohde (2011) informa que algunos líderes de Volksrevein buscaron revertir la orden de expulsión con el apoyo de las autoridades del estado de Rio Grande do Sul, en la capital Porto Alegre, y también en la, en aquella época, capital brasileña: Rio de Janeiro. Al final de mes tuvieron éxito y los alemanes y rumanos lograron permanecer en Porto Novo, y aquellos que ya habían constituido sus caravanas y dejado la región, pudieron regresar.

\section{Sobre las inmigraciones forzadas: consideraciones finales}

Daniele Conversi (2012) afirma que la primera mitad del siglo XX estuvo profundamente caracterizada por los esfuerzos de homogeneización cultural conducidos por los Estados-Nación hacia sus comunidades. De manera general, las iniciativas se basaban en la búsqueda 
de la integración de los sujetos disonantes de los ideales nacionales y en la remoción de estos mismos de los territorios pertenecientes a los Estados, lo que habría ocurrido en los casos del Holocausto, o en la migración forzada de alemanes del territorio polonés después de la Segunda Guerra Mundial (Conversi, 2012). En el caso del Estado Novo brasileño, también notamos elementos desde la perspectiva expuesta por el autor, especialmente en relación con la realidad de Porto Novo.

En este sentido, las iniciativas de integración estuvieron, en gran parte, dirigidas a los brasileños que mantenían una profunda vinculación con manifestaciones culturales alemanas, como la lengua y sus otras variaciones. El control de las instituciones escolares, las persecuciones políticas, la prohibición de habla de la lengua alemana y sus variaciones, así como los actos de incentivo al patriotismo, se oponen a esta perspectiva. Sin embargo, las migraciones forzadas, en la figura de los eventos de agosto de 1942 o de febrero de 1943, fueron una etapa más radical de la Campaña de Nacionalización en Porto Novo.

En relación con las inmigraciones de 1942, estas no surgieron de una orden específica del Estado-Nación, sino que fueron una forma de reacción ante las iniciativas que ya eran comunes en aquel periodo. En febrero de 1943, con la orden específica de las autoridades locales para la salida forzada de los extranjeros, el resultado se oponía a lo que ya había ocurrido el año anterior: la nacionalización del espacio, aunque solamente de las nacionalidades enemigas en el conflicto global. En todas ellas figuró la remoción y no la integración.

Esta perspectiva, así como los pormenores del contexto, especialmente relacionados con el origen y las particularidades de los sujetos incluidos en los procesos migratorios forzados, requiere un estudio detallado a partir de memorias. Tales tipos de fuentes ofrecen perspectivas específicas de los sujetos incluidos en los procesos estudiados, así como hacen posible una observación de la profundidad y consecuencias de las iniciativas de nacionalización promovidas por los EstadosNación. En este sentido, fue posible ofrecer un panorama de las migraciones forzadas ocurridas en Porto Novo. 


\section{Referencias bibliográficas}

\section{Fuentes Primarias}

a) Archivos

Itapiranga, P. d. (sin fecha). Livro Tombo da Paróquia de Itapiranga. Itapiranga.

b) Leyes y decretos

Brasil. (18 de março de 1939). Decreto-Lei No1.164. Rio de Janeiro, DF, Brasil.

\section{Fuentes secundarias}

a) Artículos y capítulos de libros

Conversi, D. (2012). "Nación, Estado y Cultura: por una historia política y social de la homogeneización cultural", en Historia Contemporanea, $\mathrm{N}^{\circ} 45$, pp. 437-481.

Eidt, V. (dezembro de 17 de 2020). “Josefine Wiersch", en Expressão, $\mathrm{N}^{\circ}$ 769, pp. 1-12.

Ferreira, M. d., y S. C. Pinto (2018). "A crise dos anos 1920 e a Revolução de 1930", en J. Ferreira, y L. de Almeida Neves Delgado (orgs.), O Brasil Repúblicano 1: o tempo do liberalismo oligárquico - da Proclamação da República à Revolução de 1930. Rio de Janeiro, Brasil: Civilização Brasileira, pp. 373401.

Mayer, L. (2016). "O medo e o silêncio no contexto da campanha de nacionalização (1937-1945)", en Franzen, D. O. y L. Mayer, Porto Novo 90 anos: perspectivas históricas e contemporânes. São Leopoldo, Brasil: Oikos, pp. 161-178.

Moraes, M. J. (2017). "A formação do ideal nacionalista em Santa Catarina: discursos e decretos da reforma do ensino da gestão Nereu Ramos", en J. H. Zanelatto y I. Gonçalves Alves. (orgs.), Histórias de Santa Catarina na Segunda República (1930-1945). Criciúma/Itajaí, Brasil: UNESC/UNIVALI, pp. 165-194.

Rambo, A. B. (1994). "Nacionalidade e Cidadania”, en Mauch, C. y N. Vasconcellos, Os alemães no sul do Brasil. Canoas: Ed. ULBRA, pp. 43-53. 
Rambo, A. B. (2003). "Imigração alemã na AL nos séculos 19 e 20: Argentina, Brasil e Chile", en Estudos Ibero-Americanos, Vol. 29, $\mathrm{N}^{\circ}$ 1, pp. 107-135.

Sauveur-Henn, A. S. (2010). "Die deutsche Migration nach Argentinien (1870-1945)", en Birle, P. Die beziehungen zwischen Deutschland und Argentinien. Frankfurt am Main: Vervuert, pp. 21-52.

Seyferth, G. (1994). "A identidade teuto-brasileira numa perspectiva histórica", en Mauch, C. y N. Vasconcellos, Os alemães no sul do Brasil. Canoas: Ed. ULBRA, pp. 11-27.

\section{b) Libros}

Eidt, P. (2016). Os sinos se dobram por Alfredo. Chapecó: Argos.

Gertz, R. E. (1998). O perigo alemão. Porto Alegre: Ed. UFRGS.

Gonçalves, L. P., y O. C. Neto (2020). O fascismo em camisas verdes: do integralismo ao neointegralismo. Rio de Janeiro, Brasil: FGV Editora.

Heinen, L. (1997). Colonização e desenvolvimento do oeste de Santa Catarina: aspectos sócio-político-econômicos e religiosos. Joaçaba, Brasil: Editora UNOESC.

Jungblut, R. (2011). Porto Novo: Um documentário histórico. Porto Alegre, Brasil: Letra \& Vida.

Lesser, J. (2015). A invenção da brasilidade: identidade nacional, etnicidade e políticas de imigração. São Paulo: Editora Unesp.

Levine, R. M. (2001). Pai dos pobres? O Brasil e a Era Vargas. São Paulo, Brasil: Companhia das Letras.

Mayer, L. (2017). O retrato da repressão: as perseguições a alemães no Oeste de Santa Catarina durante o Estado Novo (1937-1945). São Leopoldo, Brasil: Oikos.

Rohde, M. W. (2011). Espírito Pioneiro: a herança dos antepassados. Itapiranga, Brasil: Gráfica e Editora Porto Novo.

Spohr, I. (2016). História das casas: um resgate histórico dos jesuitas no sul do Brasil. Porto Alegre, Brasil: Padre Reus.

Stahl, W., \& L. Mayer (2019). Imagens memoráveis: cinco décadas da história de Porto Novo/Itapiranga em fotos (1926-1976). São Leopoldo, Brasil: Oikos.

Welter, I. M. (2010). Uma imigrante teuto-romena e outros escritos. Itapiranga/Florianópolis, Brasil: PEST. 
Werle, A. C. (2011). Porto Novo: o reino jesuítico germânico no oeste de Santa Catarina. Curitiba, Brasil: Editora CRV.

c) Otros

Crestani, L. (2019). História da ocupação na fronteira entre Brasil e Argentina (1881/1930). Tese de Doutorado em História Contemporânea. Évora, Portugal: Universidade de Évora.

Neumann, R. M. (2003). "Quem nasce no Brasil é brasileiro ou traidor!” as colônias germânicas e a campanha de nacionalização. Dissertação de Mestrado em História. São Leopoldo: Universidade do Vale do Rio dos Sinos.

Sausen, J. V. (2019). A nacionalização dos nacionais: as medidas estatais de nacionalização de Porto Novo (SC) durante o Estado Novo brasileiro (1937-1945). Monografia de Graduação em História. Santa Maria, Brasil: Universidade Federal de Santa Maria. 